\title{
How Political Systems Manage Their Policy Controversies
}

In October 2013, the launch of healthcare.gov, a website through which US citizens can buy health insurance, turned into an embarrassing event for the Obama administration. The website crumbled under a heavy user load and citizens were unable to create accounts. As the infrastructural centerpiece of President Obama's Affordable Care Act, the website was vital for expanding healthcare coverage to previously uninsured US citizens. Republicans, who had long opposed the Affordable Care Act, took the chaotic launch of the website as a welcome opportunity to blame the Obama administration for its ineptitude and its overall stance on healthcare. The president admitted that there was no sugar coating of the website's marred performance and promised swift improvements. The president's reaction notwithstanding, Republicans continued to blame the administration for sluggish performance improvements until the secretary of health and human services, who had overseen the website launch, resigned in April 2014.

A year later, in early summer 2015, a lobbying affair kept Swiss politics in suspense. A newspaper revealed that a member of the National Council - the lower house of the Swiss parliament - had submitted a motion under her name, which had in fact been devised by Kazakhstani party functionaries. The controversy triggered a heated discussion about remote-controlled politicians and lobbying regulations in Switzerland. Amid public blame, the parliamentarian justified her conduct but also called the proliferation of documents to Kazakhstani authorities an unfortunate mistake. Calls for disciplinary measures against the parliamentarian and for adaptations of existing lobbying regulations ultimately came to nothing.

At first glance, the chaotic launch of the healthcare.gov website and the Swiss lobbying affair do not have much in common. However, a closer examination reveals that they are examples of the same type of political event. Both instances are political "blame games" in response to policy controversies. Media consumers are intimately 
familiar with the typical political blame game. It starts with the (often accidental) discovery of a controversial event that shows that those in power and office failed to live up to agreed upon rules, standards, or previous promises. Upon this discovery, media outlets, pundits, and politicians in the opposition quickly take up the controversial event and start to assign responsibility and blame for it. Governing actors react to the controversy with excuses and explanations. Sometimes they give in to criticism and engage in activism to address it, and sometimes they kick the can down the road in the hope that the attention will quickly move on to the next controversial event on the political agenda.

Political blame games of this sort happen by the dozens in Western democracies - year in, year out. But why are blame games important? Why care about seemingly routine and minor political quarrels? In a time where big events, like the rise of populism or increased political polarization, need to be accounted for, these questions seem reasonable. Although it may be tempting to sweep political blame games under the rug of normal political competition, this book suggests doing otherwise. It proposes treating blame games as extraordinary political events, whose close study reveals how modern democratic political systems work when they come under pressure.

\subsection{Setting the Scene: When Political Systems 'Heat Up' to Address the Controversial}

Policies are ubiquitous in modern democratic political systems. This is the case because policy has become the preferred problem-solving tool of governments (Orren \& Skowronek, 2017). Modern political systems experience a constant stream of economic, demographic, technological, and societal changes. Be it financial or technological innovations like cryptocurrencies or cloning, soaring house prices or rising economic inequality, or increased levels of migration or shifting social values, all of these changes create situations that governments attempt to regulate through policy interventions. A related explanation for policy's advance is that, over time, the state has come to protect citizens against all kinds of harms, hazards, threats, and risks, ranging from disease outbreaks to industrial accidents to terrorist attacks to instances of consumer fraud (Ansell, 2019). Public demand for protection has prompted governments to respond by means of discretionary policy. As a consequence, governments now set down "prohibitions 
and requirements for everything from hiring practices to the design of entryways for private buildings to the kinds of wordings prohibited or required on consumer packaging" (Pierson, 2007a, pp. 114-115). With governments doing more over a broader range of affairs, policy infrastructure thickens, permeating almost all areas of social, political, and economic life (Adam et al., 2019; Jacobs \& Weaver, 2015; Patashnik \& Zelizer, 2013).

What unavoidably comes with a thickened and more complex policy infrastructure is an increase in the number of policy controversies. Mark Bovens and Paul 't Hart (2016, p. 654) rightly observe that only "a part of this myriad of ambitions and activities unfolds as hoped, expected and planned for by [political and administrative] policymakers. Another part throws up surprises, complications, delays, disappointments and unintended consequences." With policies all over the place, controversies about their configuration, performance, and distribution of benefits are not far behind. Some of these controversies develop into venerable political scandals; others only simmer on the political agenda before disappearing again without anybody addressing them.

What happens to policy controversies that come to the attention of politicians, citizens, and the media? How do political systems manage them? The views commonly held in the fields of political science and public policy give different answers to these questions - and both are incomplete and problematic. The political science literature overwhelmingly considers elections to be the main channel through which citizens influence the management of policy controversies. If voters take umbrage at how politicians address a policy controversy, they can vote them out of office and elect those who promise a better answer to a controversial policy issue. In this conception of politics, 'policy' is treated as a mere commodity in and residual of the 'electoral connection', a term coined by David Mayhew (1974) regarding the interactions between vote-seeking politicians and their voters. In the electoral connection, particular policy controversies usually only play a minor role. Elections have limited issue space, that is, they can only handle a very small number of political problems and policy issues simultaneously. Election campaigns in which a single policy controversy becomes crucial, like with the immigration crisis in the run-up to the 2017 German federal elections, are very rare. Only in these very rare cases is there a clear influence of elections on the political management 
of a policy controversy. Moreover, elections usually only take place every four or five years, with many policy controversies popping up in between. Therefore, with its focus on elections, dominant political science scholarship neglects, and does not grasp the consequences of, a large part of the policy controversies that democratic political systems confront over time.

The public policy literature correctly observes that political science scholarship only studies political conflict with implicit links to public policy (Weible \& Heikkila, 2017). And yet, the public policy literature also lacks an accurate view of policy controversies and their management. The reason is that it usually treats blame games as stages, or even as distracting events of other phenomena, like policy learning or crisis management. The influential works by Arjen Boin and colleagues (2008, 2009a), for example, examine the political management of crises like terrorist attacks or natural disasters. While public blame and blame management are important aspects of crisis management, they are not the main focus of these works. A somewhat different, but likewise consequential, neglect can be observed for policy process research at large. This literature is interested in the combinations of factors that produce policy change. Prominent policy process frameworks do not treat policy controversies as much more than negative focusing events (Birkland, 1998). The large-scale quantitative variant of policy process research (Baumgartner \& Jones, 2009) is especially unlikely to zoom in on the content and actual political management of policy controversies.

The diverse comparative policy literature that adopts a problemprocessing perspective, like literature on policy styles or the governance of problems, comes close to capturing, but still fails to capture, the management of policy controversies during blame games (e.g., Hoppe 2011; Howlett \& Tosun, 2019). Policy styles describe the specific ways in which particular countries address new policy problems (Howlett $\&$ Tosun, 2019; Richardson, 2014). The literature usually distinguishes policy styles along two dimensions: Whether policymakers actively address problems or react to them, and whether policymakers seek consensus with other actors involved in the policy process or if they impose their will on them. However, this line of work does not usually distinguish between more or less conflictual forms of problem processing but rather adopts a more static perspective on policy styles. As I will show, the conflictual interactions over a policy controversy that 
one can observe during blame games are markedly different from routine policymaking patterns. Blame games represent a more conflictual form of problem processing that cannot simply be derived from a country's conventional policy style. For instance, while the UK is known for its adversarial policy style, Germany is known for its much more consensual policy style. With blame games, it is just the opposite. The empirical analyses in this book will reveal that Germany exhibits a much more heated and adversarial blame game style than the UK. Therefore, overall, prominent political science and public policy scholarship ignores political blame games in response to policy controversies.

This book attempts to remedy this neglect. It treats blame games as political events in their own right whose careful study yields crucial insights into how democratic political systems cope with pressure. Much of what follows in the pages of this book finds its basis in the crucial observation that political interactions during blame games are much more conflictual than those that characterize routine political processes, like the occasional debate about pension reform or the next year's budget. Blame games are generally defined as a series of interactions between blame makers and blame takers on the occasion of a controversial political issue (Hood, 2011). I recommend thinking of them as microcosms of conflictual politics. During blame games, politics switches from competition, in which arguments are acknowledged, exchanged, and contested, to outright conflict, in which issues such as guilt, punishment, and redress take center stage. While the goals that political actors pursue during blame games are similar to those pursued during routine times - winning or conserving reputation and votes; gaining or maintaining control over policies - the strategies they apply to achieve these goals are different. Participants in a blame game attack their opponents more fiercely, portray them as utterly incompetent, depict them as guilty, and compel them to make amends. Participants in a blame game not only distort information to get their way (Jones \& Baumgartner, 2007), but they often bend the norms of democratic conduct and argue for their cause in a rather agitated fashion. Moreover, blame makers usually adopt an uncompromising stance: They are unwilling to meet blame takers halfway and want them to yield in full. Overall, the attitudes that political actors exhibit and the strategies that they adopt during blame games are very different from the attitudes and strategies adopted during routine times. Hence, 
to understand how political systems manage their policy controversies, one must appreciate the different, more conflictual, type of politics that occurs during blame games.

\subsection{Political Systems and Their Peculiar Ways of Managing Policy Controversies}

The most important and consequential insight stemming from this book is that political systems have developed peculiar ways of managing policy controversies. This is a very surprising finding given that the policy issues at the root of controversies are so diverse. With a complex and thickened policy infrastructure comes, almost by necessity, an incredibly wide range of policy controversies. They range from marred website launches to porous lobbying regulations to delayed public infrastructure projects to flawed tax reforms. The reason for management similarities across controversy types can be found in the political institutions that preset the political space in which controversy management takes place. As I will demonstrate in this book, it is important to conceive political blame games as context-sensitive events. The interactions between political actors that we observe during blame games - the blame attacks by the opposition and the blame management attempts by those in government - follow patterns that can be explained by looking at the institutional context in which blame games take place.

The best way to provisionally acquaint oneself with the different ways in which political systems manage their policy controversies is to consider an analogy. Suppose that a political system is a bit like a marriage. Actors who have a lot in common decide to spend their lives together. However, as time goes by, disagreements emerge, and conflicts must be endured. Without delving too much into couple's therapy, we can say that every marriage (or at least long-lasting ones) develops its own way of dealing with conflicts. Some couples try to swallow their anger and ignore a conflictual issue for as long as possible. Other couples reconcile their differences rather emotionally. Still, other couples, although perhaps not many, deal with conflicts in a rather unemotional and problem-oriented way. Political systems and their policy controversies follow a similar story. In some political systems, political actors try to suppress controversies for as long as possible, in others they engage in heated blame game interactions. In 
still other systems, political actors engage in rather problem-oriented blame game interactions when addressing a policy controversy.

By looking at the conflictual form of politics that blame games contain, one can learn a tremendous amount about the workings of democratic political systems under pressure. The insights that stem from the effort to understand blame games are vitally important in light of the big events mentioned earlier, like populism, elite polarization, or norm erosion, which currently cripple Western democracies and have prompted many to seriously fear for their health (Levitsky \& Ziblatt, 2018; Mounk, 2018; Snyder, 2018). As I will explain toward the end of this book, the conflictual style of politics contained in blame games resembles the type of conflictual politics that democracies are currently experiencing on a wider scale. Today, it often seems as though blame games are no longer confined to particular issues and instances but that politics as such turns into one huge blame game, with politicians violating norms and attacking each other on a daily basis. This book's explanations of conflictual politics during blame games help to make sense of conflictual politics more broadly. The more conflictual style of politics that emerges when political systems heat up to address controversial events forces us to reconsider, and eventually revise, dominant considerations about policy's role in politics and about the functioning of democracy more broadly.

\subsection{Goals and Outline of the Book}

This book provides a context-sensitive explanation of blame games and their consequences. Drawing on the analysis of fifteen blame games in the UK, Germany, Switzerland, and the USA, this book develops the first middle-range theory of these important political events.

\section{The Three Major Analytical Steps of the Book}

The book proceeds through three major steps. In the theoretical part of the book, I develop a comprehensive theoretical framework for the context-sensitive analysis and comparison of blame games. The guiding idea behind the theoretical framework is that blame games can only be properly understood by considering both the institutional factors that characterize the political system in which blame games occur and the issue characteristics that characterize the controversies at the root of 
blame games. Taking inspiration from the work of E. E. Schattschneider (1975) and Albert Hirschman (1994), I identify institutionalized forms of conflict management that Western democracies have developed to manage policy controversies. Institutional factors, namely the structures around routine political interactions in a democracy, institutionalized accountability structures, and institutional policy characteristics, act as the rules of the game that influence the broad contours of blame games and channel them in certain directions. In addition to institutional factors, I consider a second group of explanatory factors in order to account for the fact that blame games play out in front of an audience. Based on policy feedback theory (Pierson, 1993; Soss \& Schram, 2007), I identify the salience and the proximity of a controversy to average publics as the issue characteristics that determine the public's reaction to a particular blame game and the ways in which the opposition and those in government work with this reaction. A crucial advantage of this framework is that it allows for the meaningful comparison of blame games induced by a diverse set of policy controversies, ranging from food scandals to failed infrastructure projects to procurement scandals to investigation failures. The framework strikes a balance between zooming in on the content of political conflict and securing comparability across controversy types.

The theoretical framework guides and structures the empirical analysis of fifteen blame games in the second part of the book. These blame games occur within four institutional and four issue contexts. The institutional contexts consist of important aspects of the UK, German, Swiss, and US political systems. The issue contexts are four possible combinations of salience and proximity. I show how various combinations of institutional factors and issue characteristics configure different types of blame games. Institutional factors mainly determine the basic form or set-up of a blame game, that is, how participants position themselves and enter into alliances after a policy controversy has become a bone of contention. Participants in a blame game can be divided into 'opponents', who act as blame makers, and 'incumbents', within whose responsibility sphere a controversy develops. Institutional factors further influence the structure of interactions between participants, that is, political opponents' opportunities for blame attacks and the blame barriers available to incumbents. Finally, institutional factors influence the distribution of power between opponents and incumbents. In some institutional settings, 
incumbents are comfortably protected from blame and can adopt an uncompromising stance. In other settings, opponents have a better chance of damaging the reputation of incumbents or changing the course of policy during a blame game. The analysis further reveals that issue characteristics influence the content of interactions between blame game participants. What opponents say and do to attack incumbents and to attract the attention of the public and what incumbents say and do to address a controversy in the face of blame primarily depends on the salience of a controversy and on its proximity to average citizens.

The final part of the book reveals how the configurations of institutional factors and issue characteristics combine to produce blame games that vary in their consequences. For this purpose, it groups blame games according to the level of public interest that they attract and the consequences that they have for the fate of incumbents and policies. This part of the book demonstrates that when distinct controversy types pass through specific institutional systems, one of four possible blame game types can be expected to occur. This outcome reveals that a simplistic view of the relationship between the level of public interest in a blame game and the extent of consequences of it must be replaced with a more accurate (and complex) picture of blame games and their consequences. Blame games that attract the most attention from political actors, media, and the public are not necessarily those that produce significant consequences. Under particular conditions, the blame games that attract the greatest public interest only produce hot air. On the contrary, there are also blame games that slip from the view of the wider public but which nevertheless force incumbents to adjust policies. Overall, the analysis shows that political systems deal with policy controversies in idiosyncratic ways. Every political system has developed its own blame game style for managing policy controversies and does so with a wide variety of controversy types.

\section{Outline of the Book}

The remainder of this book proceeds as follows. Chapter 2 sets out to define blame games as distinct political events that protrude from routine political processes and conceptualizes the process through which a controversy becomes the object of blame game interactions. I conceptualize blame games as instances of intensified conflict during 
which political actors apply distinct sets of strategies to reach their goals. I describe both the blame-generating strategies of opponents and the blame-management strategies of incumbents. Since a variety of controversies, scandals, and (natural) crises trigger blame games in the political sphere, this chapter also revisits the question of why it is particularly important and revealing to study and understand blame games induced by policy controversies. Chapter 2 continues by introducing the theoretical framework used to explain blame game interactions and their consequences. I group the framework's explanatory factors into institutional factors and issue characteristics.

The empirical analysis conducted in Chapters 3-7 revolves around fifteen blame games that occurred in the UK, Germany, Switzerland, and the USA between 1999 and 2016. I analyze several blame games in each of these institutional contexts, each triggered by a controversy with different issue characteristics. I first examine and compare the effects of institutional factors on these blame games, and then I analyze the effects of issue characteristics. Chapter 8 then consolidates the findings into a more parsimonious typological theory of blame games and their consequences. Finally, Chapter 9 summarizes the results of the analysis and reflects on what the study of blame games implies for our understanding of politics and democracy under pressure.

\subsection{Strategy of Inquiry}

Blame games are very complex political events that require in-depth examination. At the same time, getting an idea of how democratic political systems manage their policy controversies requires a comparative approach that analyzes blame games in a variety of institutional and issue contexts. Despite pioneering work on blame games (Hood, 2011; Weaver, 1986), our understanding of these multifaceted and dynamic political events is still limited. Blame games, as spatially and temporally bounded political events (Falleti \& Mahoney, 2015), have proved to be notoriously difficult to conceptualize and study (Hinterleitner \& Sager, 2015). To date, there are no studies that analyze blame games in their entirety, that assess their consequences for the policies at their core and for the politicians involved, and that compare them across countries.

Squeezing very complex events, like political blame games, into a comparative template always involves tricky decisions about which aspects to consider in detail, which aspects to consider in passing, and 
which aspects to overlook. Selecting cases based on a theory or framework that omits important aspects could lead to selection bias. In other words, there is a possibility that one could examine and generalize about blame game styles from an "episodic, narrow, and inadequate exposure to a partial sample" of the blame game universe (Freeman, 1985 , p. 475). In the following, I briefly introduce a strategy of inquiry that can handle these difficulties. The strategy combines the contextsensitive comparison of blame games with detailed case study accounts (George \& Bennett, 2005; Mahoney \& Thelen, 2015).

\section{Method of Analysis}

To examine the effects of contextual factors on blame game interactions, I conduct a comparative-historical analysis (CHA) of each of the fifteen blame games contained in this book (Mahoney \& Thelen, 2015). A CHA treats blame games as sequences of interactions. This allows me to establish the influence of contextual factors on the specific actions of opponents and incumbents and not just on the blame game as a whole. Moreover, by situating blame games in a usually longerrunning policy struggle, one can better grasp the importance and longterm consequences of a blame game. With its reliance on case-based research, a CHA also allows me to proceed exploratively in order to bring "novel explanations to the fore" (Thelen \& Mahoney, 2015, p. 13). This is an important requirement for exposing interaction effects between contextual factors and for specifying the mechanisms through which (combinations of) contextual factors influence blame game interactions. Moreover, an inductive focus allows me to discover and accommodate idiosyncratic factors that are not captured by the theoretical framework but may nevertheless influence blame game interactions (Bennett \& Elman, 2006).

\section{Compound Research Design}

Since the fifteen blame games analyzed in this book occur in very different institutional and issue contexts, they must be arranged in ways that allow for feasible and insightful comparisons. This is achieved by arranging cases within a compound research design, which sorts contextual factors along two dimensions and then allows me to examine their respective influences on a blame game in a systematic way (Levi- 
Faur, 2004, 2006a; Vogel, 1996). As described previously, the contextual factors identified in the theoretical framework are either related to the institutional context in which the blame game plays out or to the controversy at the root of the blame game. I analyze how policy controversies are dealt with and politically processed in the UK, German, Swiss, and US political systems. The different shapes and combinations of relevant institutional factors across these systems produce major differences in blame game interactions and, therefore, constitute ideal institutional settings for comparing how democratic political systems manage policy controversies. The second dimension along which I compare blame games is the interpretive characteristics of the policies at the heart of blame games, that is, the aspects of a policy that determine the public reaction to a blame game. As I will explain in the next chapter, salience and proximity cover the most important interpretive characteristics of policy controversies that occur in modern democratic political systems. Therefore, cases that exhibit the four possible combinations of salience and proximity are representative of the spectrum of policy controversies that political systems process during blame games.

I employ a theory-driven case selection strategy that selects cases based on the independent variables contained in the framework. With four political systems and four possible combinations of salience and proximity, I can analyze and compare sixteen potential cases (corresponding to the sixteen table cells in Table 1). For a blame game to fall into a cell in Table 1 , it must possess a certain combination of contextual factors, that is, it must have occurred in a particular political system and the controversy at the heart of it must exhibit a certain combination of issue characteristics. I selected blame games that developed in response to a controversial policy issue that attracted at least a modicum of political attention and blame. Since the universe of policy controversy-induced blame games also consists of low radar blame games that do not draw too much attention and blame, only focusing on heated blame games is not an option. The intensity of the ensuing blame game interactions is deliberately ignored in order to avoid making a selection based on the dependent variable, that is, only selecting heated blame games that revolved around venerable political scandals. Moreover, I only selected blame games that political actors could not easily see coming. As I will explain in the next section, blame games for which politicians can prepare in advance exhibit a different dynamic than blame games that catch them by surprise. 


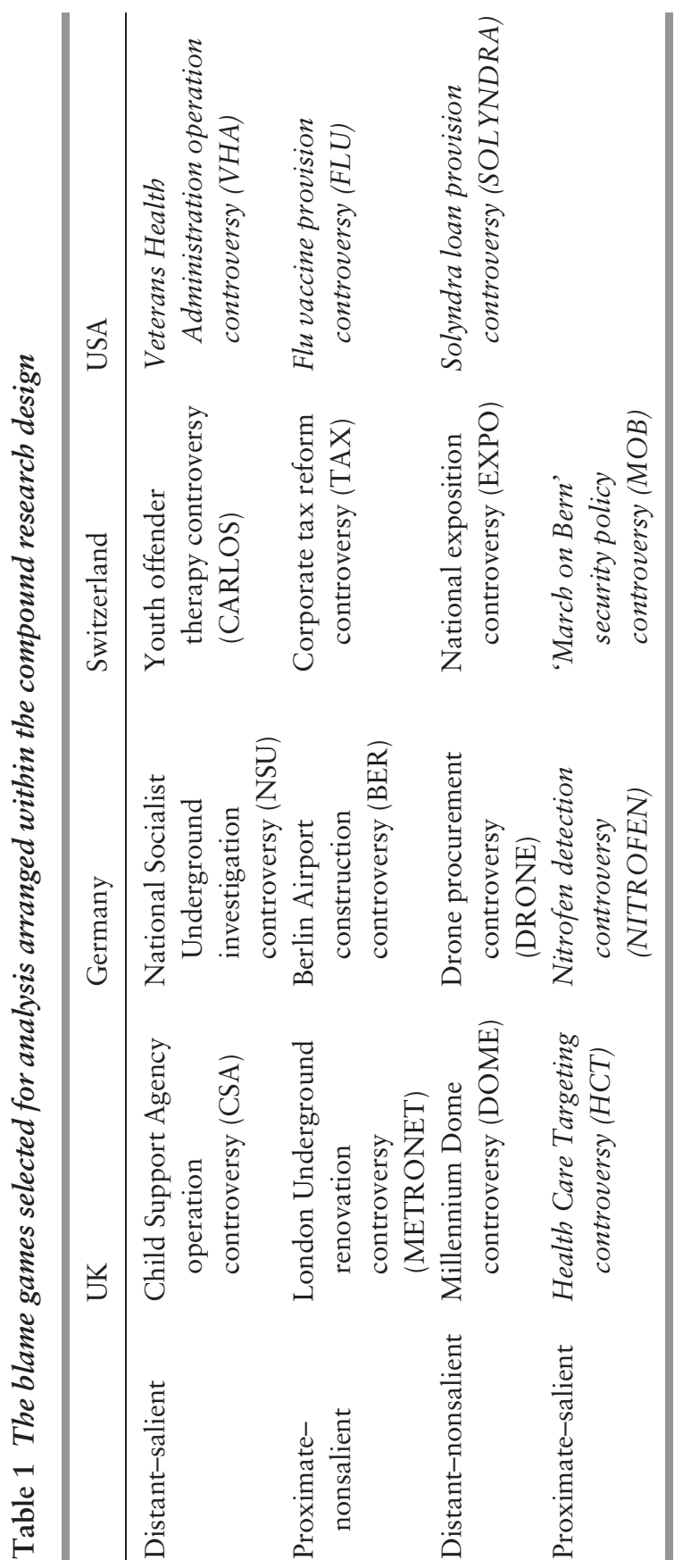


The compound research design allows for the systematic comparison of blame games situated in the same institutional context (see columns in Table 1) and of blame games where controversies exhibit similar issue characteristics (see rows in Table 1). By identifying similarities within columns, we obtain a view of how blame games typically occur in a specific institutional context, such as the German political system. Likewise, by identifying similarities within rows, we can develop a view of, for instance, a typical distant-salient blame game. The cases to be compared in a column or row exhibit commonalities in one dimension while exhibiting maximum variation in the other dimension. For example, the UK blame games analyzed are situated in the same institutional system, but they exhibit maximum variation in terms of salience and proximity. This type of comparison allows for the identification of a blame game style that applies to the full spectrum of policy controversies typically processed in the UK system. In other words, the comparisons inherent in the compound research design represent an additional protection against false generalizations.

\section{A Two-Step Analysis}

A crucial feature of the compound research design is that it allows me to divide cases into groups. I analyze one group of blame games in great detail (the nine cells in Roman font in Table 1), while another group of blame games serves as test cases for the insights derived from the analyses and comparisons of the first group of blame games (the six cells in italic font in Table 1). I study the first group of blame games in great depth to create a thorough understanding of how contextual factors influence blame game interactions (Falleti \& Lynch, 2009; Hinterleitner, 2018). At the outset of each in-depth case study, the analysis integrates the controversy leading to the blame game into a (usually) longer-running policy struggle. I then reconstruct the various interactive steps of the blame game and infer actors' blame-generation and blame-management strategies from their public accounts. Finally, I assess the influence of (combinations of) contextual factors on incentive structures and the strategy choices of the actors involved.

I analyze the UK, German, and Swiss systems in detail because the relevant institutional differences between these systems are particularly pronounced (see Table A1 in the Appendix for a systematic overview). With regard to controversy types, I examine distant-salient, proximate- 
nonsalient, and distant-nonsalient controversies in detail. These controversy types cover the large majority of controversies that occur in Western democracies. Proximate-salient controversies, like pension scandals or large-scale health scandals, are much rarer in relatively well-functioning political systems. Moreover, I seek to isolate the influence of salience and proximity on blame game interactions. This works best by analyzing and comparing cases that only exhibit one of these issue characteristics.

After analyzing the nine blame games in this way, I compare three cases in a column/row to identify the (combinations of) factors that have similar/comparable causal impact across the column/row. The result is a first impression of what a blame game in a particular institutional setting (e.g., a German blame game) or a blame game with a particular combination of issue characteristics (e.g., a distantnonsalient blame game) typically looks like. I then seek to validate and refine my first impression of blame game styles by testing the findings gleaned from the nine blame games against the remaining six blame games. For example, I test whether, and to what degree, the conclusions drawn from the comparison of the three Swiss cases can be validated in the fourth Swiss case, the blame game about the 'March on Bern' security controversy.

Dividing the fifteen blame games into groups may seem to be an unnecessary complication of the empirical analysis, but it is not. The testing step that is built into the compound research design further increases my confidence that the blame game styles derived from the comparisons of the nine in-depth cases are accurate and generalizable to other cases with the same institutional or issue context. Unlike the three in-depth cases, whose detailed analysis creates strong internal validity, the test cases allow me to systematically target external validity, thus further increasing confidence in the generalizability of the findings (LeviFaur, 2006b). Overall, the theoretical framework, the theory-driven case selection strategy, and the compound research design with its testing step combine to form a powerful analytical strategy that yields reliable and generalizable results about blame game styles.

\section{Data and Measurement}

The fifteen case studies in this book draw on a vast volume of qualitative data systematically coded and analyzed with Nvivo 10 software. 
The data is collected from four data categories that together provide ample evidence of the influence of institutional factors and issue characteristics on blame game interactions. First, I analyze official documents, such as transcripts of debates in parliaments and committees, parliamentary initiatives, inquiry reports, official publications, and press releases to reconstruct how blame game actors interact with each other and with the public. ${ }^{1}$

Second, I draw on background literature on political systems and policy sectors (e.g., on cultural policy in Switzerland, which is relevant in the EXPO case), as well as on background literature on broader political and societal developments (e.g., on the peculiar relationship between Germany and its army, which is relevant for the DRONE case; or the UK's New Public Management reform trajectory, which plays a role in some of the UK cases). Background literature helps me to determine institutional factors and the salience and proximity of a controversy. I made qualitative assessments of the salience and proximity of a policy controversy prior to the start of a blame game to guard against tautological reasoning (i.e., to measure them before they become distorted by the blame generation and blame management approaches of political actors). ${ }^{2}$

The third source of data is the comprehensive media coverage of blame games. For each case, a rather conservative quality paper, a more liberal paper, and a tabloid paper are analyzed. ${ }^{3}$ The consideration of the intensity, variation, and tone of media coverage allows me to measure the public's reaction to a blame game (public feedback). Media may of course misrepresent the reaction of the public (e.g., through bad reporting or by covering a blame game more intensively than the true public interest in that blame game would suggest). However, I argue that a lack of first-hand information on the public's reaction does not carry much weight in light of the present research context. I am ultimately interested in how blame game actors perceive the public's stance and how they react in response. How blame game actors perceive the public's reaction mostly happens through the media. The amount of and variation in coverage reveals how interested different parts of the public are in a blame game. If there is significant tabloid coverage of a blame game in addition to significant quality coverage, one can safely assume that the wider public - and not just the societal elite - is watching the blame game. ${ }^{4}$ The tone of the coverage discloses whether a controversy is perceived to be salient or not. 
Personalized and emotional coverage signals that the public perceives a controversy to be salient while problem-oriented and unemotional coverage indicates that a controversy is perceived to be nonsalient. ${ }^{5}$

Finally, where available, I consult polls held by news agencies during a blame game. Polls are a way for blame game actors to directly sense the public's attitude toward a blame game. Polls thus provide a more direct measure of the public's attitude than media coverage. 